Proceedings of SPIE, Vol. 3710, April 1999

\title{
Experimental investigation of the acousto-electromagnetic sensor for locating land mines
}

\author{
Waymond R. Scott, Jr. ${ }^{a}$ and James S. Martin ${ }^{b}$ \\ ${ }^{\mathrm{a}}$ School of Electrical and Computer Engineering \\ ${ }^{\mathrm{b}}$ School of Mechanical Engineering \\ Georgia Institute of Technology \\ Atlanta, GA 30332
}

\begin{abstract}
A hybrid technique is presented that simultaneously uses both electromagnetic and acoustic waves in a synergistic manner to detect buried land mines. The system consists of an electromagnetic radar and an acoustic source. The acoustic source causes both the mine and the surface of the earth to be displaced. The electromagnetic radar is used to detect these displacements and, thus, the mine. To demonstrate the viability of this technique, experimental models have been constructed. The models use an electrodynamic transducer to generate an acoustic surface wave, a tank filled with damp sand to simulate the earth, simulated mines, and a radar to measure the vibrations. The technique looks promising; we have been able to measure the interactions of the acoustic waves with both simulated antipersonnel mines and antitank mines buried in damp sand. We have measured strong resonances in some of the mines; these resonances are shown to help differentiate the mine from clutter.
\end{abstract}

Keywords: land mine, mine detection, acoustic, ground penetrating radar, GPR

\section{INTRODUCTION}

Seismic/elastic techniques show considerable promise for the reliable detection of all types of buried mines, even low-metal anti-personnel mines. The reason for this is that mines have mechanical properties that are significantly different from soils and typical forms of clutter. For example, the shear wave velocity is approximately 20 times higher in the explosive and the plastics used in typical mines than in the surrounding soil. In addition, mines are complex mechanical structures with a flexible case, a trigger assembly, air pockets etc. The complex structure gives rise to structural resonances, non-linear interactions, and other phenomenology that is atypical for both naturally occurring and man made forms of clutter. Thus, this phenomenology can potentially be used to distinguish a mine from clutter. However, seismic detection techniques have fallen into disfavor because of practical system implementation issues.

A system has recently been developed at Georgia Tech that exploits the advantages of seismic techniques while overcoming many of the implementation issues [1-3]. The configuration of the system currently being studied is shown in figure 1. The system consists of an electromagnetic radar and an acoustic source. The source preferentially generates an acoustic surface (seismic) wave in the earth. The acoustic wave causes both the mine and the surface of the earth to be displaced. The displacement of the mine is different from the earth's, because the acoustic properties of the mine are quite different than those of soil. The displacement of the surface of the earth when a mine is present is different than when it is not present because of the local and propagating waves scattered by the mine. The electromagnetic radar is used to detect these displacements and, thus, the mine.

The technique is both complimentary to and compatible with existing mine detection techniques. It offers an additional queue for detection and classification because it senses different physical phenomena than conventional mine detection techniques such as ground penetrating radars (GPRs), metal detectors, and infrared sensors. There 


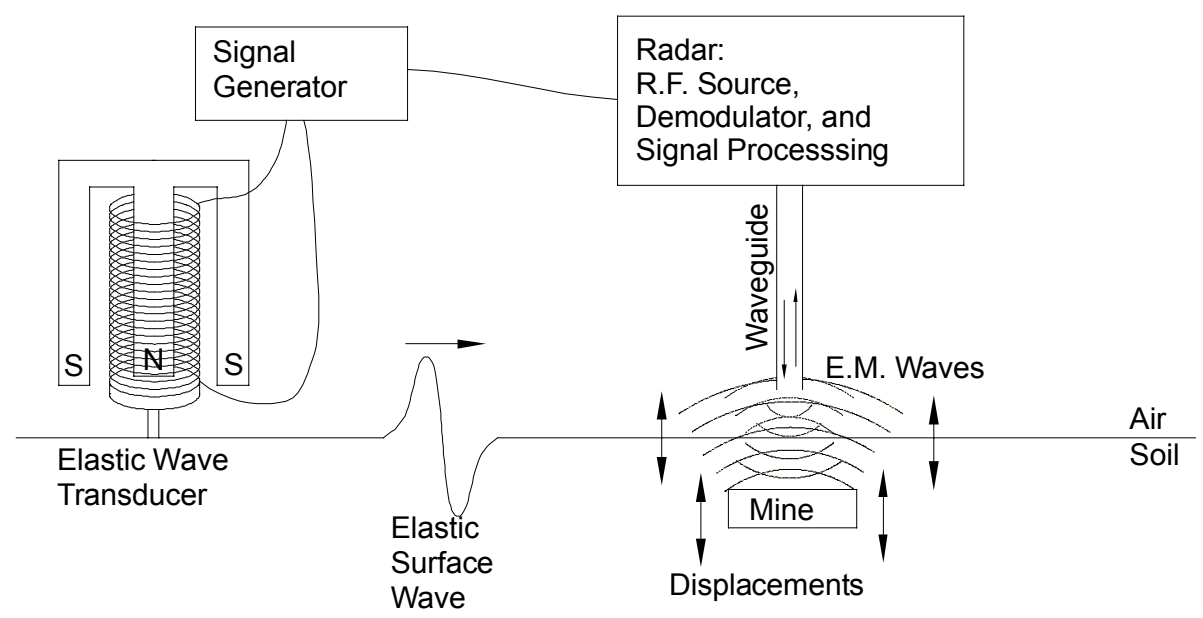

Figure 1. Acousto-electromagnetic mine detection system with the acoustic transducer placed on the surface of the earth.

is also no reason why the operation of the seismic source or sensor would preclude the simultaneous operation of these types of systems. This makes a seismic system an excellent candidate for sensor fusion with other techniques.

Experimental models for the system have been constructed and automated. The experimental models are being used to demonstrate the viability of the technique and to study the interactions of the acoustic and electromagnetic waves with various types of buried mines. The technique looks promising; detections have been demonstrated for both simulated antipersonnel mines and antitank mines buried in damp sand, and strong mine resonances have been observed in some of the experimental data which could serve to classify the detected objects. Additional investigation is needed to determine the potential capabilities of the technique in more varied conditions.

\section{FIRST EXPERIMENTAL MODEL}

Two experimental modes have been constructed; a drawing of the top view of the first experimental model is shown in figure 2. The model consists of a wooden tank that is filled with damp sand that has been packed to a relatively uniform density and cohesion. The tank is approximately $120 \mathrm{~cm}$ wide, $120 \mathrm{~cm}$ deep, and $240 \mathrm{~cm}$ long. A transducer is placed on the surface of the sand and is used to launch the elastic waves into the sand. The transducer is an electrodynamic shaker that is driven with a signal generator. The transducer has been coupled to the surface of the sand with a narrow base plate so that it preferentially excites elastic surface waves. These surface waves travel across the surface of the tank and interact with a mine that is buried in the sand.

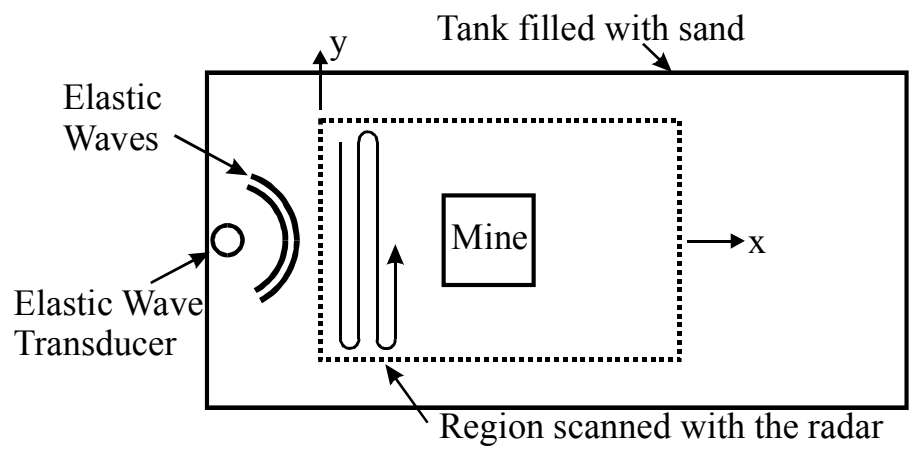

Figure 2. Top view of experimental model. 
A radar has been designed and built to measure the acoustic vibrations of the soil and the mine. The two biggest challenges to make this radar perform adequately for the mine detection system are 1) to make it sufficiently sensitive to be able to detect small vibrations, and 2) to make the spot size (the area on the surface illuminated by the electromagnetic waves) sufficiently small to detect high wavenumber surface waves and localized wave fields. The radar can measure vibrations as small as $1 \mathrm{~nm}\left(10^{-9} \mathrm{~m}\right)$ as currently configured. To obtain this sensitivity, the radar was designed to minimize the effects of noise, such as the phase noise of the source and the electromagnetic interference from low-frequency magnetic fields. The spot size of the radar must be smaller than half of a wavelength of the acoustic waves at the highest operating frequency in order not to spatially integrate out the motion of interest. Currently, a small spot size is obtained by using an open-ended waveguide as the antenna for the radar. This antenna produces a sufficiently small spot size when the open end of the antenna is placed within a few centimeters of the surface. A digital beamforming array is being investigated as a possible method for obtaining a small spot size when the height of the antenna is increased [4]. All of the results in this report were obtained with the radar operating at $8 \mathrm{GHz}$ and the end of the waveguide about 1 to $2 \mathrm{~cm}$ from the surface.

A $x-y$ positioner is used to scan the radar over the surface of the sand. This is controlled by a personal computer which automatically scans the radar over the surface and records the data. The region scanned with the radar is indicated on figure 2. Displacements are measured in this region as a function of frequency and position. The measurements are made on a uniform rectangular grid of discrete positions in the scanned region. The grid consists of 41 points in the y-direction that are spaced $2 \mathrm{~cm}$ apart and 121 points in the $\mathrm{x}$-direction that are spaced $1 \mathrm{~cm}$ apart, for a total of 4961 points. Displacements are measured and recorded as a function of drive frequency at each of these points. Previously reported measurements [1-3] were made using short pulses in the time domain; the measurements reported here were made using a network analyzer in the frequency domain. This greatly improved the signal to noise ratio without increasing measurement times. The frequency domain data are transformed into the time domain in post processing, using a differentiated gaussian pulse with a center frequency of $400 \mathrm{~Hz}$ as the incident signal.

The current emphasis is on data integrity rather than scan time. The current scan time of 24 to 48 hours can be reduced greatly by reducing the integration time, increasing the distance between sample positions on the surface, or arraying the radar so that multiple positions can be measured simultaneously. For example, a scan could be completed in 5 to 10 minutes, if the integration time were reduced by a factor of 8 , the spacing between the points were increased by a factor of 2 in each direction, and the radar were arrayed to take 10 measurement points simultaneously.

\section{EXPERIMENTAL RESULTS}

To date, the experimental model has been used to study the interaction of the elastic waves with seven different mines, both simulated mines and real mines that have been made inert by removing the explosive. A list of the mine with their approximate dimensions is shown in table I. The simulated anti-tank mine is made out of a solid piece of acrylic plastic, and the SIM9 mine is a case from a $9 \mathrm{~cm}$ diameter simulated antipersonnel mine partially filled with glazing putty to model the explosive. The results for the first two mines are presented in the previous papers [1-3], and the results for the remaining mines will be presented next.

A waterfall graph of the displacement of the surface is presented in figure 3 for the TS-50 mine when the top of the mine is $1.3 \mathrm{~cm}$ below the surface of the sand. In this graph, the displacement is plotted as a function of time for the 121 points spaced along the $x$-axis with $y=0$ (along the center of the scanned region). The plot for each of these 121 points is shifted vertically from the previous one. The plot for $x=0$ is at the bottom of the graph and the plot for $x=120 \mathrm{~cm}$ is at the top of the graph. The region in which the mine is located is indicated in gray. The incident pressure wave is seen to propagate toward and across the mine. The incident surface wave is also seen to travel across the mine. The larger displacements above the mine are due to a resonance in the mine. The resonance makes it much easier to detect the mine. The travelling waves reflected from the mine are relatively small indicating the difficulty that would be encountered in detecting this mine using a classical pulse echo 
technique. A pseudo color graph of the frequency spectrum is shown in figure 4 as a function of $\mathrm{x}$ with $\mathrm{y}=0$. The higher intensities near $\mathrm{x}=22 \mathrm{~cm}$ are due to the resonance. The effect appears to be due to several resonances which occur in the 400 to $700 \mathrm{~Hz}$ frequency range. The specific spectral components of the effect may constitute a target signature for the TS-50 mine. It is apparent from figures 3 and 4 that the higher frequency waves attenuate more rapidly than do the lower frequency waves. In the absence of the resonance, a higher frequency incident would be required to image an object the size of the TS-50 mine. Thus, the resonance effect extends the distance from the source over which detections of this type of mine can be made.

\section{Table I Mines investigated.}

\begin{tabular}{|c|c|c|c|}
\hline & Type & Description & Size \\
\hline 1 & AT & Simulated anti-tank mine & $30 \mathrm{~cm}$ wide, 30 long, $7.5 \mathrm{~cm}$ height \\
\hline 2 & EM-3 & Simulated anti-personnel mine & $7.5 \mathrm{~cm}$ diameter, $2.5 \mathrm{~cm}$ height \\
\hline 3 & TS-50 & Inert anti-personnel mine & $8 \mathrm{~cm}$ diameter, $4.5 \mathrm{~cm}$ height \\
\hline 4 & VS-50 & Inert anti-personnel mine & $8 \mathrm{~cm}$ diameter, $4.5 \mathrm{~cm}$ height \\
\hline 5 & Butterfly & Inert anti-personnel mine & $4 \mathrm{~cm}$ wide, $12 \mathrm{~cm}$ long, $1.8 \mathrm{~cm}$ height \\
\hline 6 & M-14 & Inert anti-personnel mine & $5 \mathrm{~cm}$ diameter, $4 \mathrm{~cm}$ height \\
\hline 7 & SIM9 & Simulated anti-personnel mine & $9 \mathrm{~cm}$ diameter, $3 \mathrm{~cm}$ height \\
\hline
\end{tabular}

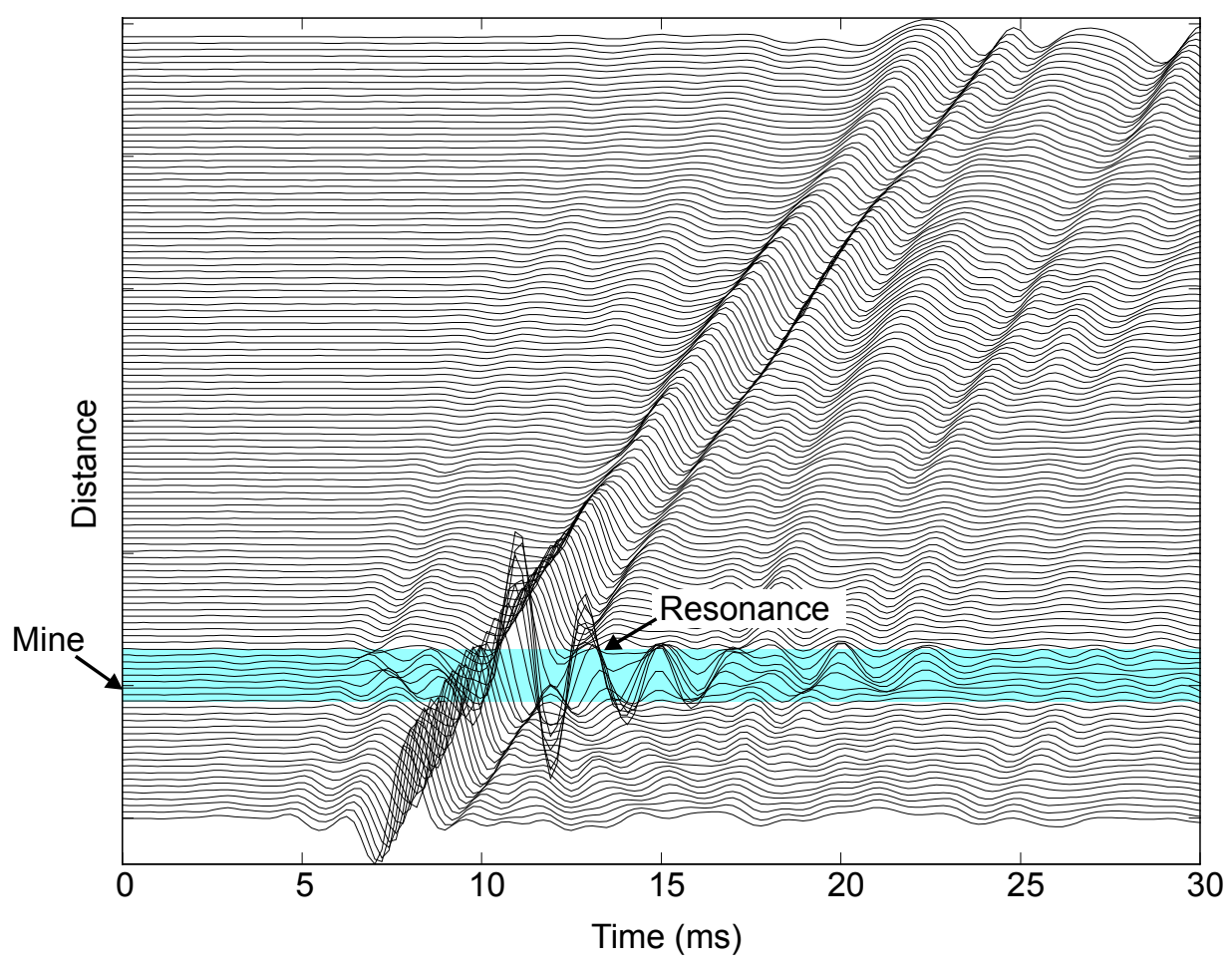

Figure 3. Waterfall graph of the displacement of the surface of the sand when the TS-50 anti-personnel mine is buried in the sand with $y=0$. The top of the mine is $1.3 \mathrm{~cm}$ below the surface. 

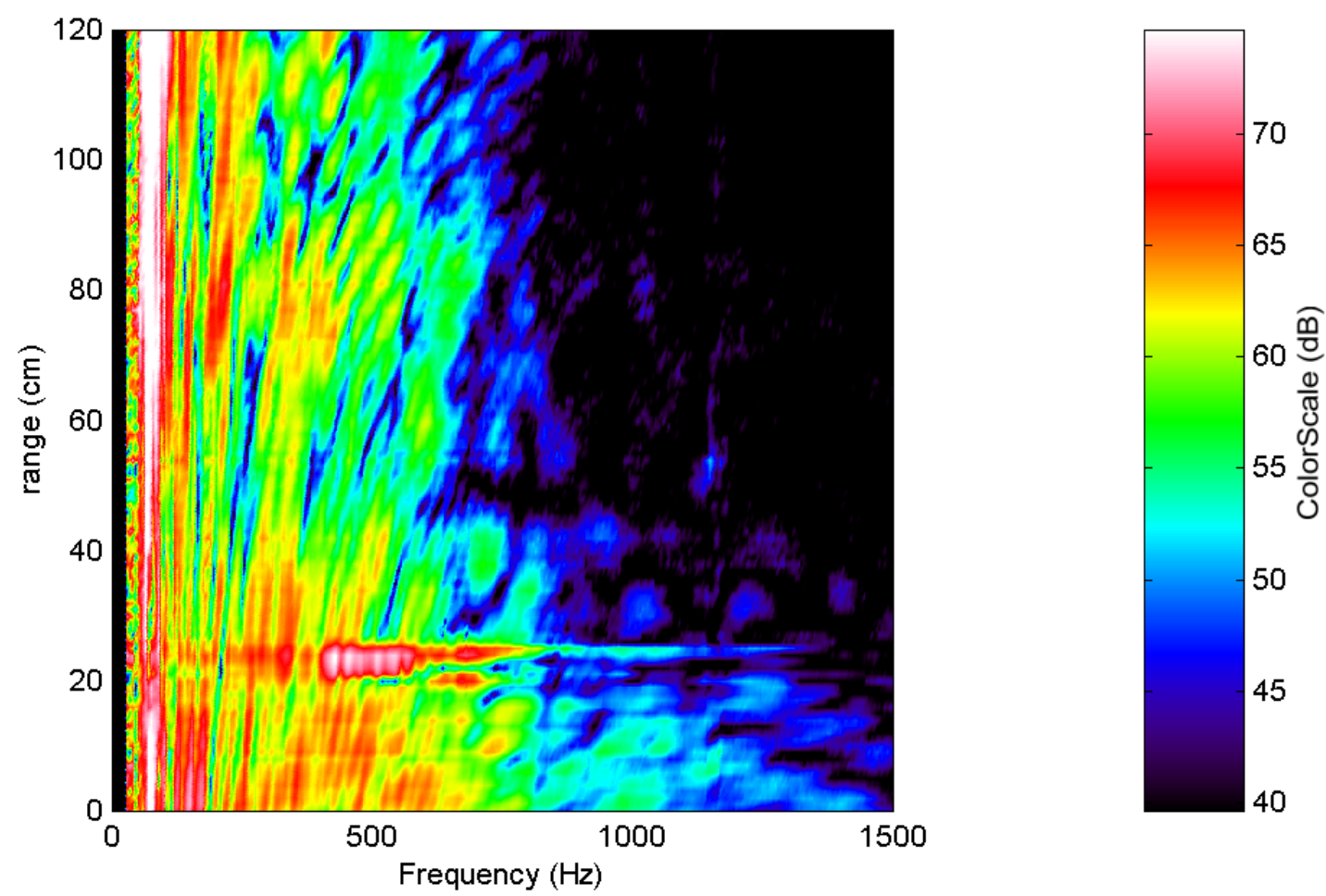

Figure 4. Pseudo color graph of the amplitude of the frequency spectrum for the surface displacement of the sand when the TS-50 anti-personnel mine is buried in the sand with $\mathrm{y}=0$. The top of the mine is 1.3 $\mathrm{cm}$ below the surface.

Pseudo color graphs of the amplitude of the displacement of the surface are presented in figure 5 for the entire scanned region at a time at which the waves are interacting with the mine. The displacements are shown for the raw data and for the data with the forward traveling waves filtered out [1]. The mine can be seen in the graphs with and without the forward traveling waves filtered out. However, the effect of the mine is much more obvious in the graph with the forward traveling waves filtered out. The displacements due to the resonance and the reflected waves are clearly visible. A single image formed from the entire scanned region and the full

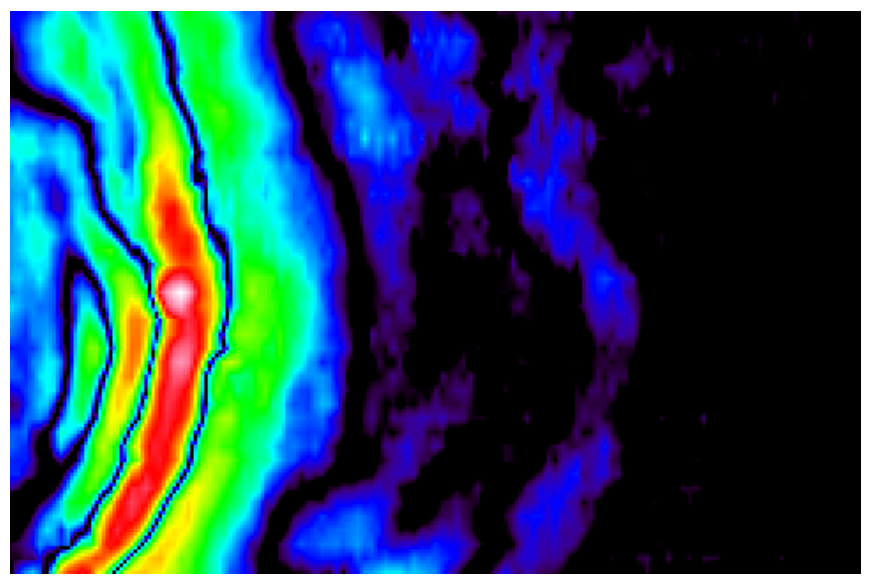

a)

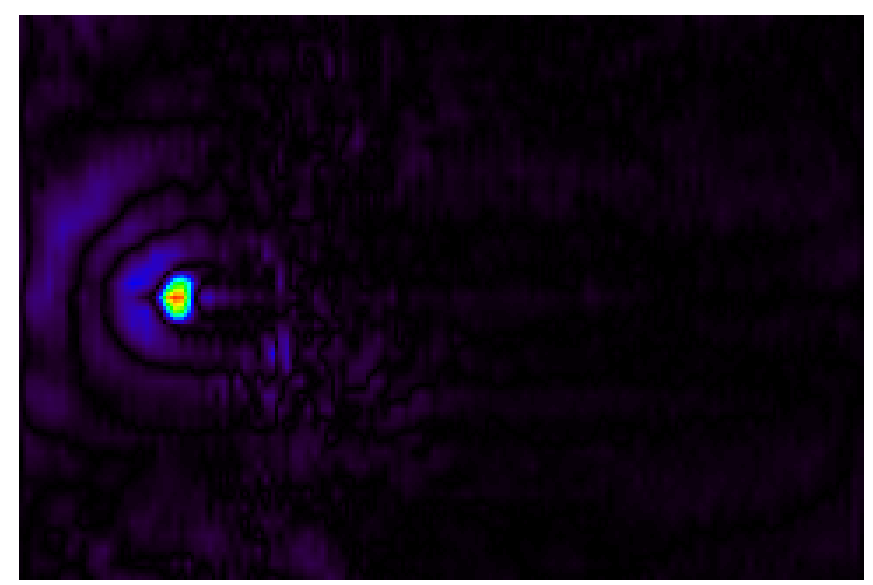

b)

Figure 5. Pseudo color graph of the amplitude of the displacement of the surface: a) raw measured data and b) data with the forward traveling waves filtered out. The top of the TS-50 mine is $1.3 \mathrm{~cm}$ below the surface. 
measurement time by viewing the back propagating waves excited near the arrival time of the incident (thus rejecting the back wall reflection from the tank) is shown in figure 6 . The location, shape and relative size of the mine can be seen in the image.

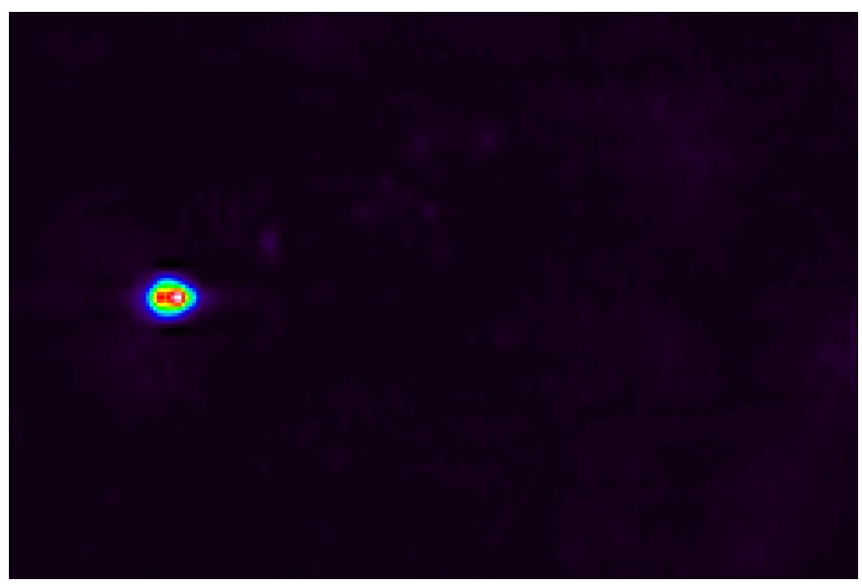

Figure 6. Image formed from the experimental results when the TS-50 anti-personnel mine is buried in the sand. The top of the mine is $1.3 \mathrm{~cm}$ below the surface.

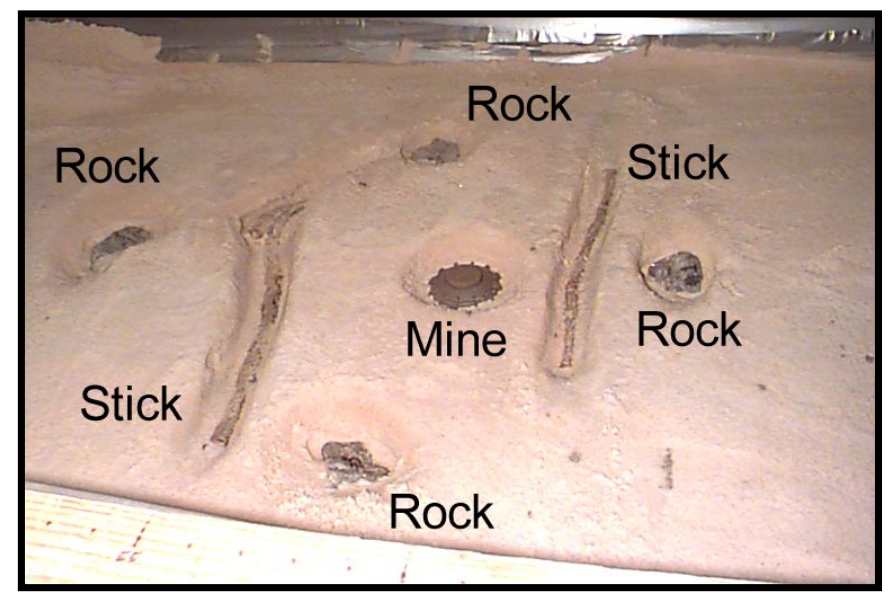

Photograph with the mine and the clutter uncovered.

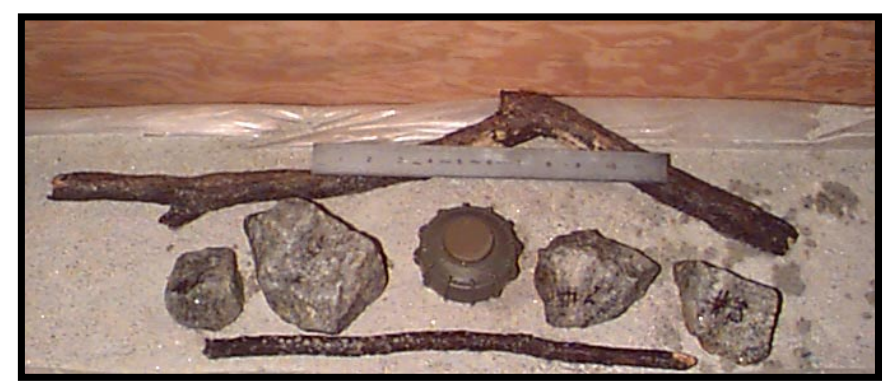

Photograph showing the relative size of the mine and the clutter objects.

Figure 7. Photograph of the TS-50 mine surrounded by clutter. The top of the mine and the clutter is approximately $1.3 \mathrm{~cm}$ below the surface. 
Another experiment was performed with this mine to see how well it could be differentiated from some common types of clutter. In this experiment, the mine was buried along with three buried rocks and two buried sticks; they were all buried approximately $1.3 \mathrm{~cm}$ deep. The mine and the buried clutter can be seen uncovered in the upper photograph in figure 7. The relative size of these objects can be seen in the lower photograph. Pseudo color graphs of the amplitude of the displacement of the surface are presented in figure 8 for the entire scanned region with the forward traveling waves filtered out. The time is chosen so that the incident pulse has reached the mine and the reflected pulses are clearly seen. An image formed from the data taken from the experiment is shown in figure 9. The location, shape and relative size of the mine can be clearly seen in the image; however, none of the clutter objects can be seen. Thus, the mine can be clearly differentiated from the clutter. The reason the mine is evident while the clutter is not is because the mine exhibits a resonance and the clutter objects do not. It is probable that all types of mines will exhibit similar resonances, but it is unclear if these will be manifest in the soil surface displacements or at what frequency they will occur. This is clearly an area for further investigations.

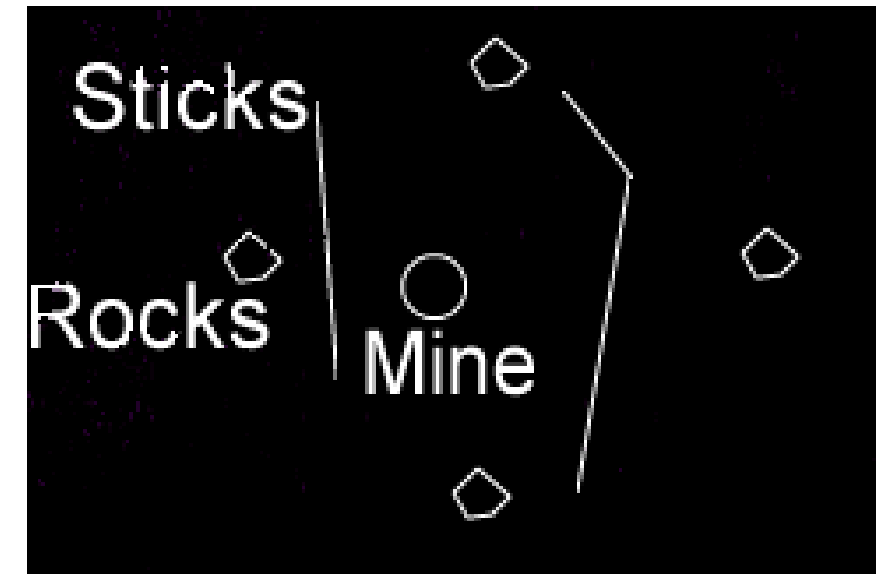

a)

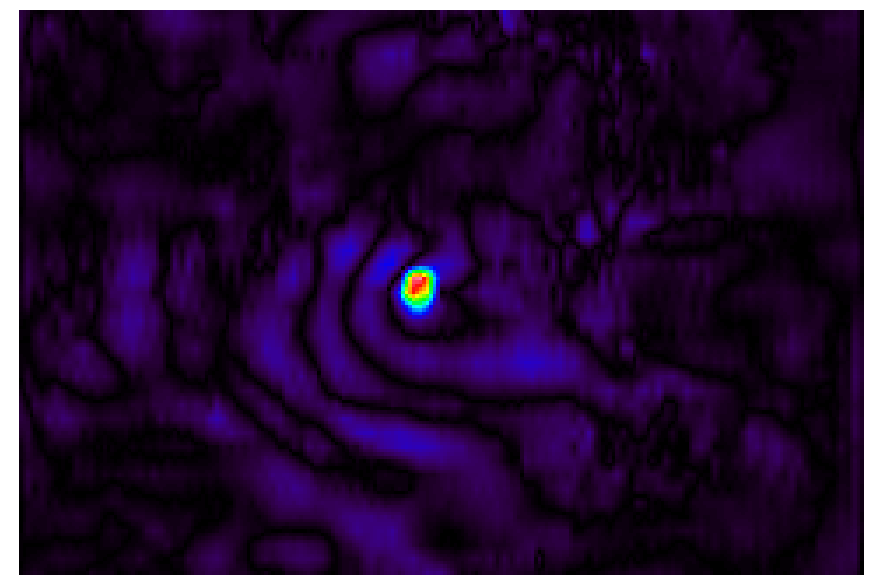

b)

Figure 8. a) Diagram showing the location of the mine and the clutter; b) Pseudo color graph of the amplitude of the displacement of the surface with the forward traveling waves filtered out. The top of the TS50 mine is $1.3 \mathrm{~cm}$ below the surface.

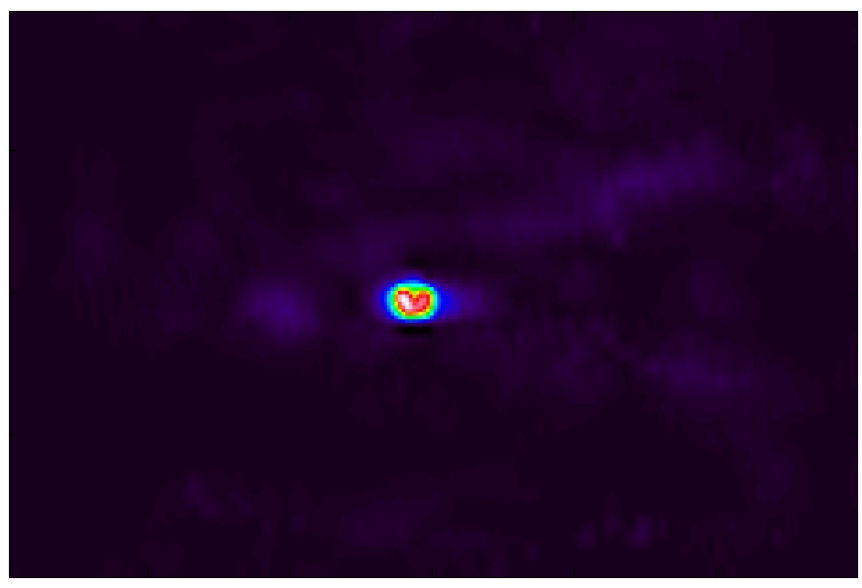

Figure 9. Image formed from the experimental results when the TS-50 anti-personnel mine is buried in the sand surrounded by clutter items ( 3 rocks and 2 sticks). The top of the mine and the clutter items is approximately $1.3 \mathrm{~cm}$ below the surface. 
Waterfall graphs of the displacement of the surface are presented in figure $10 \mathrm{a}$ for $\mathrm{y}=0$ (along the center of the scanned region). Graphs for 5 different mines as well as a graph without a mine are presented in the figure. The top of the mines is $6 \mathrm{~mm}$ below the surface of the sand. A time window of approximately $15 \mathrm{~ms}$ that follows along with the traveling wave is shown for each graph. The incident wave can be seen to propagate toward and across the buried mines. The wave in the no mine case is seen to propagate relatively undisturbed. Note, however, that it experiences significant dispersion as it travels through the sand. The wave can be seen to be disturbed in all of the cases in which a mine is buried. The disturbances are largest for the TS-50 and the butterfly mine, and the disturbances are smallest for the M-14 mine. Waterfall graphs of the same data with the forward traveling waves filtered out are presented in figure $10 \mathrm{~b}$. The waves seen in these graphs are due to both the reflected waves and local effects of resonances in the mines. The waves are seen to be significant for all of the mines, and insignificant for the no mine case. Thus, it is clearly possible to detect all of these mines.

\section{NEW EXPERIMENTAL MODEL}

The model presented above was designed with the primary consideration of the speed with which it could be built and instrumented. The model has performed well, but with the increasing refinement of the experiments several shortcomings of the model have become apparent. These problems were each addressed in the design of the new improved experimental model. A photograph of the new experimental model is shown in figure 11. The new model is much larger than the original one: the tank is approximately $4.5 \mathrm{~m}$ wide, $1.5 \mathrm{~m}$ deep and $4.5 \mathrm{~m}$ long; and is filled with 50 tons of packed damp sand. A larger faster positioner that can scan in the $\mathrm{x}, \mathrm{y}$, and $\mathrm{z}$ directions was incorporated into the model. The positioner is mounted $1.5 \mathrm{~m}$ above the surface of the sand with a large supporting frame to facilitate the larger standoff distances needed to test the beamforming arrays which are being investigated. The method for taking the data has also been changed. The data is taken in the time-domain using a swept frequency pulse ("chirp") that is temporally compressed in post processing. The new method is approximately 10 times faster while maintaining an adequate signal to noise ratio due to reduced ring-down time required at each measurement location. An additional gain in signal to noise ratio in the new model is provided by a larger source which drives the surface with 5 times the force of the acoustic source used in the first model.

The size of the first tank and the nature of its geometry and boundary conditions led to an artificially poor signal to reverberation ratio. This imposed as many limits as the signal to noise problem and resulted in restrictions on the time window for the measurement and repetition rate at which signals could be transmitted. Because of its increased size and lack of in band structural resonances the new tank greatly improves the signal to reverberation ratio. Also, the nature of the reverberation in the first tank varied with the depth of the water table in the sand. Since this could only be measured by disturbing the sand and could only by modified by the evaporation or addition of water there was considerable variation between measurements in the reverberation floor. This has been improved in the new tank with the addition of a drainage system that allows the depth of the water table to be measured and water to be both added and removed without disturbing the sand. Thus the reverberation floor is also more stable in the new experimental model. A comparison of a measured wave travelling in the old and new models is shown in figure 12. The wave in the new model is clearly cleaner. The reflections from the sides are not evident in the new model; they are the diagonal waves seen in the graph for the old model. The wave fronts are also straighter; this is due to the decreased measurement time and method of scanning.

In the past concerns had been raised over the validity of wet compacted sand as a surrogate for soil. Published data generally indicates higher shear wave speeds for soils than those that were measured in the damp compacted sand. This data, however, was taken under different conditions than those of interest for the mine detection problem and usually involves lower frequencies and deeper measurement locations. Prior to the construction of the new model field measurements around the Georgia Tech campus were made which confirmed that in the frequency range of interest soils have roughly the same surface wave speeds as those which have been observed in the sand $(70-80 \mathrm{~m} / \mathrm{S})$. The only reasonable soil surrogate which could be shown to have a significantly higher surface wave speed (artificially crushed granite) cohered so tightly that mine burial would have been nearly impossible. 

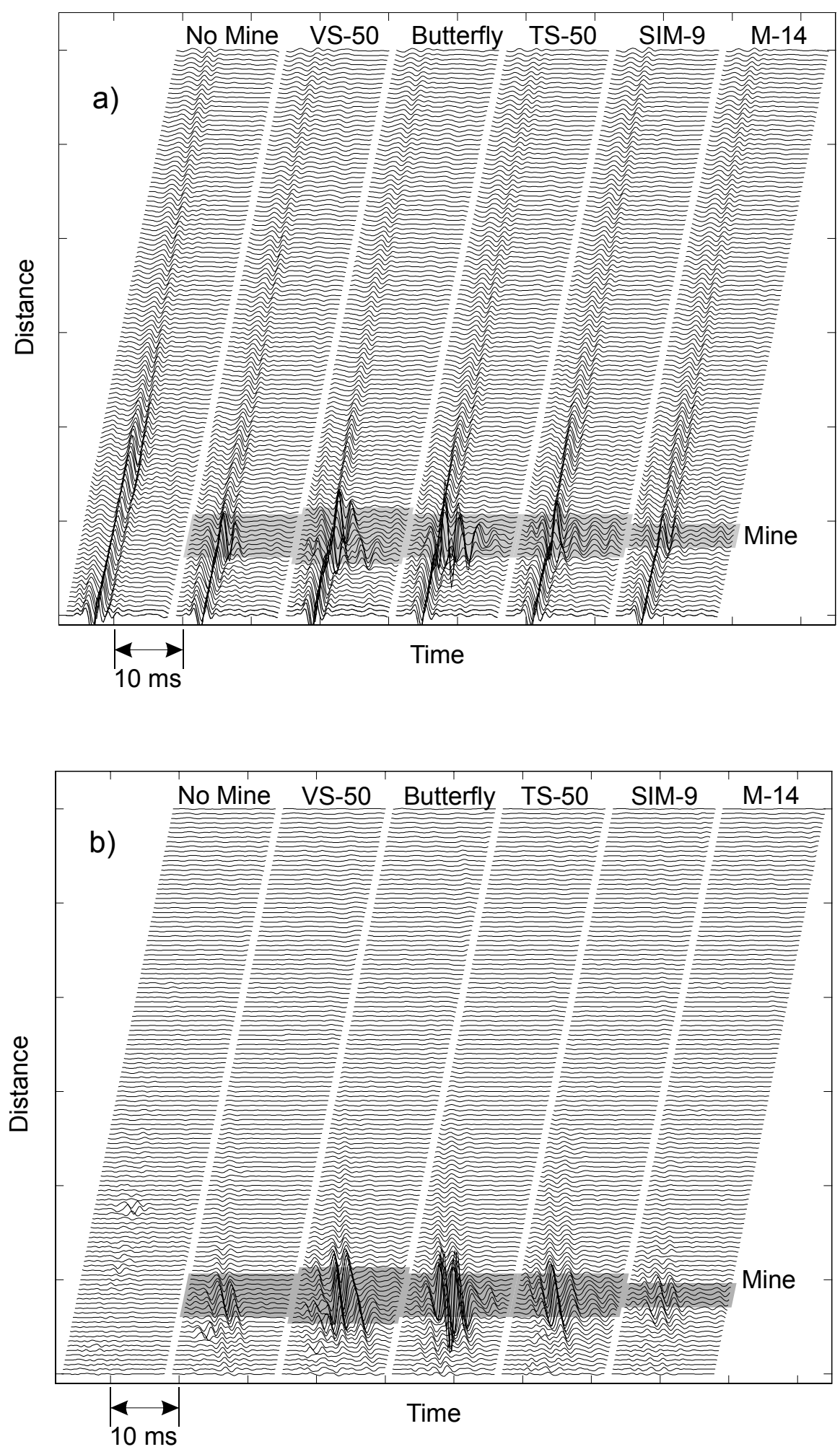

Figure 10. Waterfall graph of the displacement of the surface of the sand for a variety of anti-personnel mines are buried in the sand with $y=0$. The top of the mines are $0.6 \mathrm{~cm}$ below the surface. 


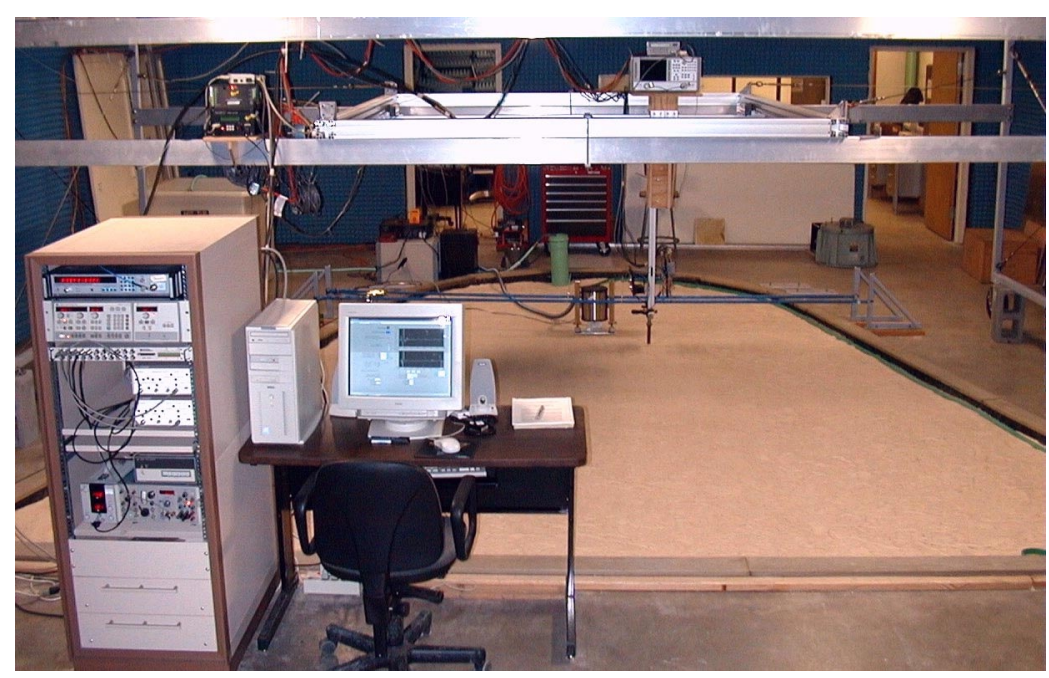

Figure 11. Photograph of the new experimental model.

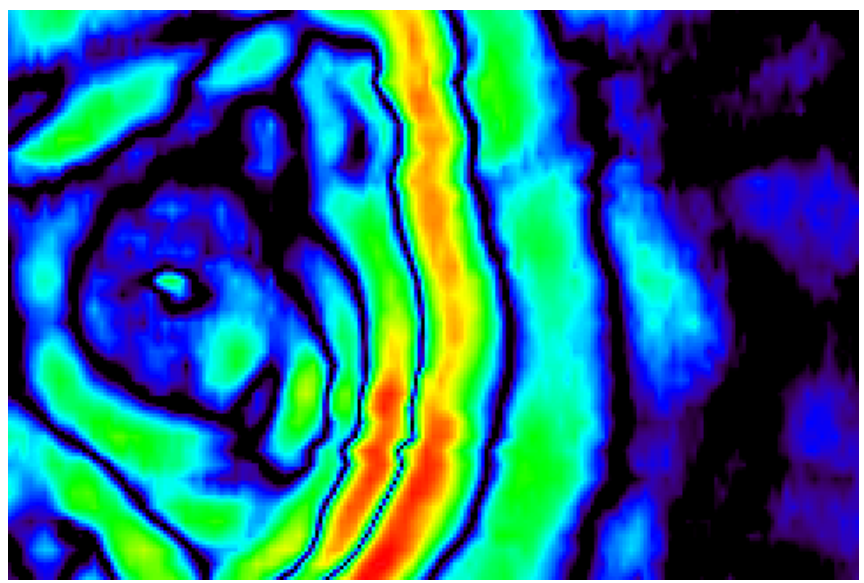

a)

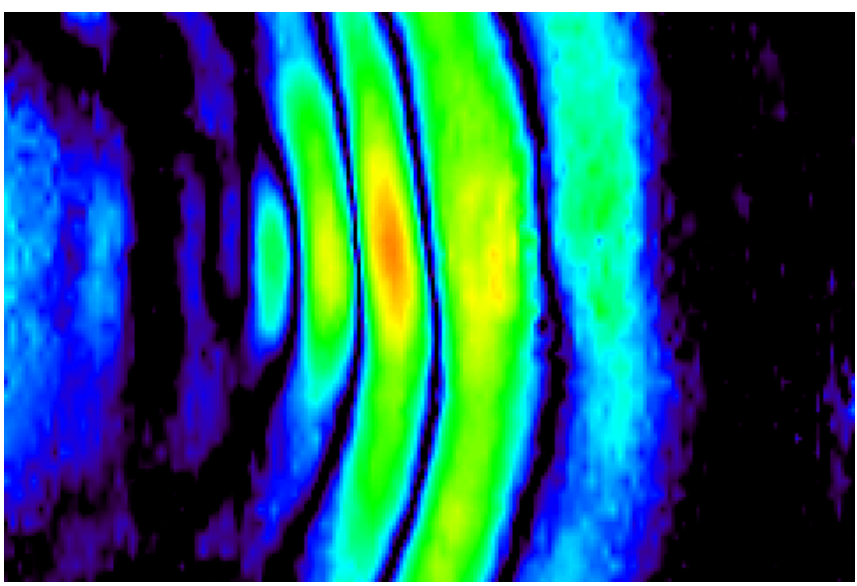

b)

Figure 12. Pseudo color graph of the amplitude of the displacement of the surface for a) the old experimental model and b) the new experimental model.

\section{CONCLUSIONS}

Experimental models for the acousto-electromagnetic sensor have been constructed and used to investigate the viability of this technique. The technique looks promising; it has been shown to be capable of detecting both simulated antipersonnel mines and antitank mines buried in damp sand. It has also been shown to be capable of distinguishing an antipersonnel mine from some types of naturally occurring clutter. However, much more work is needed to understand the capabilities of the sensor in more varied conditions.

\section{ACKNOWLEDGEMENTS}

This work is supported in part under the OSD MURI program by the US Army Research Office under contract DAAH04-96-1-0048 


\section{REFERENCES}

1. Scott, W.R., Jr., Schroeder, C., and Martin, J.S., "An Acousto-Electromagnetic Sensor for Locating Land Mines," SPIE, AeroSense, Detection and Remediation Technologies for Mines and Minelike Targets III, Orlando, FL, pp. 176-186, April 1998

2. Scott, W.R., Jr. and Martin, J.S., “An Experimental Model of an Acousto-Electromagnetic Sensor for Detecting Land Mines," Proceedings of the 1998 IEEE Antennas and Propagation Symposium, Atlanta, GA, pp. 978-83, June 1998.

3. Scott, W.R., Jr., Schroeder, C., and Martin, J.S., "A Hybrid Acoustic/Electromagnetic Technique for Locating Land Mines," Proceedings of the 1998 International Geoscience and Remote Sensing Symposium, Seattle, Washington, July 1998

4. Lee, S.H. and Scott, W.R., Jr., "Beamforming Array for Detection Buried Landmines," SPIE, AeroSense, Detection and Remediation Technologies for Mines and Minelike Targets III, Orlando, FL, , April 1999 